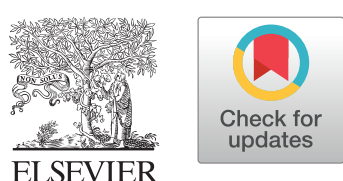

\title{
Review
}

\section{Deliver Cardiac Virtual Care: A Primer for Cardiovascular Professionals in Canada}

\author{
Jeffrey Lam, MB, BCh, BAO, ${ }^{a}$ Kamran Ahmad, MD, MSc, FRCPC, \\ Kenneth Gin, MD, FRCPC, FCCS, ${ }^{c}$ and Chi-Ming Chow, MDCM, MSc, FRCPC, FCCS ${ }^{b}$ \\ ${ }^{a}$ Division of Internal Medicine, Kingston Health Sciences Centre, Queen's University, Kingston, Ontario, Canada \\ ${ }^{b}$ Division of Cardiology, St Michael's Hospital, University of Toronto, Toronto, Ontario, Canada \\ ${ }^{c}$ Division of Cardiology, Vancouver General Hospital, University of British Columbia, Vancouver, British Columbia, Canada
}

\begin{abstract}
The COVID-19 pandemic, with its need for distancing, has necessitated the use of virtual care in never-before-seen volumes. This review article aims to provide a primer on virtual care for cardiovascular professionals in Canada. The technology to facilitate remote patient interactions is already available, but barriers exist. Adequate and effective cardiac virtual care must be further developed given the need for rapid evaluation and close ongoing follow-up of patients, as seen in the areas of management of heart failure, cardiac rehabilitation, electrophysiology, and hypertension. Many Canadian organizations have published resources to assist health care providers and patients
\end{abstract}

The technology needed to deliver health care remotely has been available for decades, ${ }^{1}$ with varying degrees of successful incorporation into everyday workflow. The COVID-19 pandemic forced a widespread, expedited implementation of virtual care, dramatically changing the way health care is delivered in the span of weeks, especially in March 2020, when the pandemic started. Virtual care (VC) is any interaction between patients and their health care providers that uses information and communication technologies to facilitate remote delivery of care. ${ }^{2}$ Virtual care can be delivered via numerous methods that include, but are not limited to, phone calls, text messages, and encrypted videoconference software platforms such as Zoom, WebEx, Microsoft Teams, and Google Meet.

Even before the COVID-19 pandemic, interest in virtual care was growing because of an anticipated shortage of health

Received for publication August 11, 2021. Accepted October 4, 2021.

Ethics Statement: The research reported has adhered to the relevant ethical guidelines.

Corresponding author: Dr Chi-Ming Chow, St. Michael's Hospital, 30 Bond Street, Toronto, Ontario M5B 1W8, Canada. Tel.: +1416 864-5201; fax: +1-416-864-5330.

E-mail: Chi-Ming.Chow@unityhealth.to

See page 155 for disclosures.

\section{RÉSUMÉ}

Dans le contexte de la pandémie de COVID-19 et de la distanciation sociale qu'elle impose, le recours aux soins de santé virtuels a atteint des sommets historiques. Le présent article de synthèse est une introduction aux soins de santé virtuels destinée aux professionnels de la santé cardiovasculaire du Canada. La technologie permettant de faciliter les interactions à distance avec les patients existe déjà, mais il y a des obstacles à sa mise en œuvre. Des soins de santé virtuels adéquats et efficaces doivent être développés davantage en cardiologie compte tenu de la nécessité d'une évaluation rapide et d'un suivi étroit et continu des patients, notamment quand il est question care professionals, combined with the public's desire to seek efficient and convenient means of receiving health care. ${ }^{3,4}$ Cost reductions and improved access to equitable care have also been cited as drivers to develop a framework for providing virtual care. ${ }^{1}$ Although these initiatives were enthusiastically promoted as a novel means of delivering patient care, they were also met with concerns regarding compromised quality of care from both health care providers and patients.

This review article provides a primer for cardiovascular health care professionals on delivering virtual care in Canada. We also identify barriers and discuss how cardiac care may be delivered in the future. We examine virtual care as it is being implemented in cardiac rehabilitation, electrophysiology, management of heart failure, and hypertension.

\section{The Current Canadian Climate}

Canadian citizens are technologically more connected than ever before. According to the 2016 Canadian General Social Survey (GSS), 76\% of Canadians aged 15 and older own a smartphone; ${ }^{6}$ this number increased to $88.1 \%$ by 2018 . Statistics Canada found that, on average, $91.3 \%$ of Canadians had at least occasional Internet use in 2018, with the highest percentage in British Columbia at $94 \%$ and the lowest in Newfoundland and Labrador at $86 \%{ }^{8}$ These figures are 
navigate the unfamiliar virtual care landscape. Although there are concerns surrounding issues such as patient privacy, access to technology, language discrepancies, and billing, these deficits provide opportunities for growth by health care organizations and technology companies. The integration of virtual care, home-based devices, and disruptive technologies emphasize the trend toward virtualization of health care, with the potential for greater personalization of health care interactions and continuity of care. Funding models were rapidly developed at the beginning of the COVID-19 pandemic, and although some provinces have deemed these changes as permanent, the status from other provinces remains unknown. The foundations to support virtual care as a key modality for health care delivery in Canada have been built, and further developments may strengthen its viability as a long-term option. de prise en charge de l'insuffisance cardiaque, de réadaptation cardiaque, d'électrophysiologie ou d'hypertension. De nombreux organismes canadiens ont publié des ressources pour aider les fournisseurs de soins et les patients à trouver leurs repères dans l'univers peu connu des soins de santé virtuels. Les questions telles que la protection des renseignements personnels des patients, l'accès à la technologie, les différences linguistiques et la facturation soulèvent des préoccupations. Néanmoins, les lacunes constituent des possibilités de croissance pour les organismes de soins de santé et les entreprises technologiques. L'intégration des soins de santé virtuels, des dispositifs à domicile et des technologies perturbatrices met en lumière la tendance à la virtualisation des soins de santé, allant de pair avec la possibilité d'accroître la personnalisation des interactions et la continuité des soins. Des modèles de financement ont été rapidement élaborés au début de la pandémie de COVID-19. Bien que certaines provinces aient reconnu le caractère permanent des changements; la position des autres provinces demeure inconnue. Les conditions de base sont réunies pour que les soins de santé virtuels soient reconnus en tant que modalités clés de la prestation des soins de santé au Canada, et d'autres développements pourraient en renforcer la viabilité en tant qu'option à long terme.

COVID-19 pandemic, uptake of such programs was poor, with only $10 \%$ to $35 \%$ of eligible patients participating and high participant dropout rates. ${ }^{15,16}$ Commonly cited barriers to participation in cardiac rehabilitation in person included program availability (particularly in nonurban regions) and personal motivation. ${ }^{15-17}$ Furthermore, no Canadian cardiac rehabilitation programs existed solely via digital means before COVID-19. ${ }^{1}$

Virtual cardiac rehabilitation (VCR) programs have been proposed as a potential alternative and supplement to traditional hospital-based cardiac rehabilitation. Several studies before the COVID-19 pandemic investigated the feasibility and role of VCR. A randomized controlled trial conducted in British Columbia ${ }^{17}$ involved a 16 -week program consisting of weekly online tasks, logging health data using wearable heart rate trackers and home blood pressure monitors; 1-on-1 virtual sessions with a nurse case manager, dietitian, and exercise specialist; and exercise prescriptions with dietary recommendations. VCR led to an increase in exercise capacity, defined by an increase in maximal time on a Bruce protocol treadmill test. There was an improvement in cholesterol and nonsignificant reductions in hospital visits but no significant change in body mass index. Other studies of VCR have shown improvements in cardiovascular disease risk factors and exercise capacity comparable with hospital-based cardiac rehabilitation. ${ }^{15,17}$ No long-term VCR data are available to assess the effect on cardiac events and mortality. Further studies are needed to investigate the impact that widespread implementation of VCR during the COVID-19 pandemic has had on cardiac rehabilitation outcomes.

Although the VCR framework developed by Lear et al. was being implemented in 2018 as part of health care services in Fraser Health Authority, British Columbia, ${ }^{10}$ the COVID-19 pandemic revealed new challenges in implementation of VCR. One important challenge was patient risk stratification, as graded exercise testing remains an important component of identifying high-risk individuals to ensure appropriate moni-

toring and exercise regimens, but access during the pandemic
Cardiac rehabilitation programs are interprofessional initiatives that are an effective means of secondary prevention for patients with cardiovascular disease. ${ }^{14}$ However, before the 
was severely limited, as exercise tolerance testing can only be performed in-person at present. ${ }^{2}$ Within the United Kingdom, there was a 3-fold increase in patients receiving home-based cardiac rehabilitation during the COVID-19 pandemic. ${ }^{19}$ In the United States, adherence was found to be comparable with hospital-based cardiac rehabilitation with some studies reporting significantly higher adherence to home-based virtual programs. ${ }^{19}$ Additional studies are needed to identify recruitment retention and compliance, particularly in Canada.

Studies are also being conducted on cardiac rehabilitation in pediatric populations. Khoury et al. investigated the utility and safety of a custom ergometer that incorporates a video game platform, live audiovisual feed, electrocardiogram, and pulse oximeter to allow for remote medical supervision of cardiac rehabilitation in youth with Fontan physiology. This study found similar physiological responses between the custom remote monitored ergometer compared with standard ergometer cardiopulmonary exercise tests. ${ }^{20}$ Future studies on its cost effectiveness and scalability in remote pediatric rehabilitation are needed before widespread adoption.

\section{Electrophysiology}

Although the field of electrophysiology has long used remote technology in the form of ambulatory heart rhythm monitors and implantable devices with remote transmission capability, studies on the efficacy of CVC in patients with arrhythmia are limited. ${ }^{4}$ In the past, efforts to implement virtual technology have increased physician burden and even decreased efficiency, which has limited the proportion of CVC in everyday practice. ${ }^{4,21,22}$ However, following the mandatory implementation of CVC in the midst of the COVID-19 pandemic, patient and physician opinions on its utility are shifting. A prospective survey conducted at Cleveland Clinic regarding patient and physician experience following a CVC appointment in electrophysiology clinic found that $59 \%$ of patients and $68 \%$ of physicians preferred having CVC for the next appointment, with $91 \%$ of patients being able to successfully complete their CVC. ${ }^{4}$ The use of wearable and ambulatory devices is known to be useful in collection and dissemination of patient data to their health care teams. Some studies have suggested that remote device monitoring may even reduce mortality and hospitalization. ${ }^{23}$ However, patient access to such technology may be limited by cost. ${ }^{4}$ Although there are costs associated with obtaining necessary equipment, they may be offset from decreased travel and lost productivity. A study conducted at the Barts Heart Centre in the UK, assessing the feasibility of CVC in patients with atrial fibrillation postablation, found that $80 \%$ of patients reported significant travel cost and time savings, with potential hospital budget savings as well. ${ }^{24}$

Other aspects of CVC management of atrial fibrillation have been studied. Patient education on symptomatology, management options, and lifestyle changes surrounding their arrhythmia is frequently reported to be lacking, ${ }^{25}$ and the use of CVC as a means of patient education may improve patient outcomes and satisfaction. Using CVC for anticoagulation management in patients with atrial fibrillation who require warfarin has been associated with fewer thromboembolic events when compared with management of anticoagulation, which relies on in-person laboratory and provider visits. ${ }^{25,26}$

\section{Heart failure}

Patients who have heart failure require particularly close monitoring because of the high risk of rehospitalization with a significant burden of morbidity, mortality, and health care expenditure. $^{27-30}$ Developing strategies for self-monitoring and regular CVC follow-up (such as virtual wards) may reduce readmissions. ${ }^{31}$ The use of wearable activity monitors, blood pressure monitors, $\mathrm{Wi}-\mathrm{Fi}$, or Bluetooth enabled weight scales, and mobile based apps are important means of acquiring physiological data to assess progress, but patients may face barriers of cost and technological literacy, preventing the use of these devices. ${ }^{30}$ Regular CVC appointments provide opportunities for patient education and feedback on lifestyle changes while also allowing clinicians to address issues of noncompliance and identify early indicators of decompensation. ${ }^{29}$ Health care providers may make medication changes during the CVC appointment or advise the patient to seek in-person medical attention if indicators of heart failure decompensation are present.

Exercise is an important aspect of management of heart failure in the community, and adherence remains a challenge that requires further studies to determine the effectiveness of remote-based interventions. ${ }^{30}$ In spite of this, $\mathrm{CVC}$ - in conjunction with home-based health-monitoring devices-shows promising early data (such as improved exercise capacity) and highlight the importance of direct and ongoing involvement with the patient to reduce disease burden, although further study is needed. ${ }^{28,30}$

\section{Hypertension}

Hypertension is a well-known significant modifiable risk factor of morbidity and mortality in cardiovascular disease. ${ }^{32}$ Thus, appropriate, accurate, and cost-effective management of hypertension remains an important component of patient care. Twenty-four-hour blood pressure monitoring is deemed the gold standard in diagnosis of hypertension. ${ }^{33}$ The use of ambulatory blood pressure monitoring has been supported by all international guidelines as an important component of management of hypertension, with home monitoring deemed preferable over clinic blood pressure measurements. ${ }^{34}$ A study conducted in Scotland found that remote monitoring of home blood pressure readings was associated with decreased appointment times and improved control of blood pressure. ${ }^{35}$ Although self-monitoring in isolation may not significantly alter hypertension, combining this longitudinally collected data with appropriate health care provider interventions may lead to improved management of blood pressure. ${ }^{36} \mathrm{CVC}$ (telemonitoring) combined with home blood pressure monitoring has been found to be a costeffective strategy. ${ }^{37}$

Despite these benefits, uptake of routine remote blood pressure monitoring in Canada remains low. This is, in part, because of lack of funding or billing codes for remote blood pressure monitoring that discourage clinicians from engaging in routine remote blood pressure monitoring practices. Furthermore, although blood pressure monitoring devices are subject to baseline international standards outlined by the International Organization for Standardization (ISO) and Institute of Electrical and Electronics Engineers (IEEE), different grades of products exist that exhibit significant 
Table 1. Advantages and disadvantages of virtual care $\mathrm{c}^{10,13,39,55}$

Advantages
- Ability to maintain continuity of care during socially-distanced
pandemic times
- Increases access to care and specialized programs, particularly those in
geographically diverse locations
- Reduction in travel time and costs associated with attending offices,
clinics, or hospitals
- Enables more frequent and flexible follow-ups and remote patient
monitoring
- Availability of consumer technologies (eg, KardiaMobile [AliveCor,
Mountain View, CA], A\&D Medical Heart Track [San Jose, CA]) to
- enable virtual care and remote monitoring
Reduction in some provider health care costs such as decrease in over-
Disadvantages
- Requires technological literacy of patients and health care professionals
or personalized upfront patient education to be familiar with the use of
- Rechnology
- Inability to perform direct observation and physical examinations
- Limited digital access in rural areas, within older populations, and lower
- Issues with language barriers
- Concerns with potential compromise of privacy and patient confidentiality
IT, information technology.

differences in regulation and accuracy, such as comparing consumer and clinical grade devices. Organizations such as Hypertension Canada have provided listings for validated devices (https://hypertension.ca/bpdevices). ${ }^{38}$ Management of hypertension in CVC should be a priority, given its significant health effects and the effectiveness of treatment.

A summary of the advantages and disadvantages of virtual care use can be found in Table 1 . Table 2 provides an overview of the common technologies used in virtual care.

\section{Barriers and Challenges}

\section{Patient confidentiality}

Handling large volumes of sensitive patient information via virtual platforms raises privacy concerns. The exponential uptake of virtual care within a short period of time may expose security gaps. As virtual care is used to manage increasing numbers of patients, it will undoubtedly require more stringent regulations and policies. ${ }^{3,21}$ Daily practices and data storage must comply with the Personal Information Protection and Electronic Documents Act (PIPEDA); details on how PIPEDA enables data security is beyond the scope of this review article, but further information can be found at https://www.priv.gc.ca/en/privacy-topics/privacy-laws-in-canada/ the-personal-information-protection-and-electronic-documentsact-pipeda/. Although patients may avoid using virtual platforms for various reasons, privacy concerns are still commonly cited. ${ }^{39}$ Physicians may be targeted for cyber attacks, given that they have access to confidential information; thus, health care providers should be adequately trained in patient privacy and cybersecurity. ${ }^{40}$ Physicians should also be aware that recording by the patient of the physicianpatient interaction is becoming increasingly common. Canadian Medical Protective Association (CMPA) had issued a warning regarding this. ${ }^{41}$
Careful steps must be taken to minimize the risk of interception of health data. Communication involving sensitive information should occur with end-to-end encrypted platforms in private settings. Data should be stored in secure and encrypted by 2-factor authentication. Ensuring security patches are frequently updated can further mitigate the possibility of data breaches. ${ }^{40}$ Patients must also be aware of their own roles in preventing unwanted dissemination of data, such as attending virtual care in a private setting and using personal Internet connections instead of public guest Wi-Fi connections. Patients should be educated about these precautions before their appointments. Maintaining workflow efficiency without sacrificing patient confidentiality remains an ongoing challenge that must be addressed adequately. Provincial privacy commissioners have published guidelines for ensuring privacy while practicing virtual care. For example, guidelines have been published for Ontario (https://www.ipc.on.ca/wpcontent/uploads/2021/02/virtual-health-care-visits.pdf), British Columbia (https://www.doctorsofbc.ca/managing-your-practice/practice-supports/privacy-toolkit), and Québec (https:// www.quebec.ca/en/health/health-system-and-services/telehealth/ telehealth-practice).

Patients should be consented before the virtual encounter in a manner that is easy to understand, regardless of previous knowledge on confidentiality practices and virtual care. A short standardized consent form prepared by CMPA is available to be used for clinicians to obtain consent when initiating virtual care encounters: https://www.cmpa-acpm.ca/ static-assets/pdf/advice-and-publications/risk-managementtoolbox/com_16_consent_to_use_electronic_communication form-e.pdf.

The Ontario Medical Association (OMA) has also provided a document for the consenting process and documentation: https://www.oma.org/uploadedfiles/oma/media/member/ membermappedpdfs/vc-consent.pdf

\section{Inequities and digital divide}

The digital divide, defined as inequality in access to technology, ${ }^{42}$ continues to be a challenge. The issue is multifaceted. A portion of patients lack consistent, reliable access to technology to participate in virtual care, whereas some patients have limited digital literacy. A study conducted at the University of Pennsylvania found that patients who completed virtual care appointments were more likely to be younger, female, and to be English speaking. ${ }^{13}$ More specifically, patients who participated in video encounters tended to be younger, Caucasian, and had higher median household income. ${ }^{13}$ Patients from a lower socioeconomic status may have less access to Internet, personal communication devices, or reliable mobile phone data plans. ${ }^{43,44}$ Unfortunately, a large portion of economically disadvantaged patients are also the ones who suffer from multiple comorbidities and would stand to benefit even more from convenient ongoing follow-up of medical conditions, such as via local clinics that have telemedicine equipment set up already with personal help to gain virtual access to specialists that are located elsewhere. A good example is the Ontario Telemedicine Network (otn.ca).

The rapid rate at which new technological advances appear makes digital literacy a necessity, but it also makes it challenging to consistently stay current with technology. One of 
Table 2. Advantages and disadvantages of common communication technology integrated with virtual care ${ }^{3,10,40}$

\begin{tabular}{|c|c|c|}
\hline Communication modality & Advantages & Disadvantages \\
\hline Telephone & $\begin{array}{l}\text { - Widely available and low cost } \\
\text { - Real-time interaction with improved patient engagement }\end{array}$ & $\begin{array}{l}\text { - Cannot see patients' facial expressions, body language, and } \\
\text { physical signs. Cannot have a "general overview" of the } \\
\text { patient } \\
\text { - Requires scheduling and needs to be synchronous } \\
\text { - Reception issues with certain areas } \\
\text { - Language barriers } \\
\text { - Inability for data capture }\end{array}$ \\
\hline Text messaging & $\begin{array}{l}\text { - Asynchronous and provides time to provide response } \\
\text { - No scheduling required } \\
\text { - Relatively inexpensive }\end{array}$ & $\begin{array}{l}\text { - Only small amounts of information can be transmitted at one } \\
\text { time } \\
\text { - Limited patient engagement } \\
\text { - Intrusion into health care professionals' nonworking time } \\
\text { - Privacy issues with nonsecure applications (eg, WhatsApp) }\end{array}$ \\
\hline Video conference & $\begin{array}{l}\text { - Real-time communication with better patient engagement } \\
\text { - Can see patients' expressions and may perform limited } \\
\text { physical examinations/observations } \\
\text { - Can have multiple parties attend simultaneously, including } \\
\text { family members and other health care professionals }\end{array}$ & $\begin{array}{l}\text { - Requires scheduling and has to be synchronous } \\
\text { - Requires specific hardware and software and thus is more } \\
\text { costly to set up and maintain } \\
\text { - Requires stable internet connection and reasonable speed and } \\
\text { bandwidth }\end{array}$ \\
\hline Web-based applications & $\begin{array}{l}\text { - Can capture and visualize large amounts of clinical data } \\
\text { - Convenience of access not limited by location or } \\
\text { synchronicity } \\
\text { - Opportunity for data capture and transfer }\end{array}$ & $\begin{array}{l}\text { - Requires specific hardware and software and thus is more } \\
\text { costly to set up, maintain, and implement } \\
\text { - Requires higher degree of technological literacy } \\
\text { - Requires internet connection }\end{array}$ \\
\hline Smartphone applications & $\begin{array}{l}\text { - Ability to capture real-time biometric data such as heart rate, } \\
\text { exercise frequency and intensity } \\
\text { - Portable, and convenience of access not limited by location } \\
\text { - Opportunity for data capture and transfer }\end{array}$ & $\begin{array}{l}\text { - Requires specific hardware and software and thus is more } \\
\text { costly to set up, maintain, and implement } \\
\text { - Requires higher degree of digital literacy } \\
\text { - Requires internet connection and data plan }\end{array}$ \\
\hline
\end{tabular}

the most common reasons that patients avoid using virtual platforms for health care is the desire to speak directly to their health care providers in person rather than via remote interactions. ${ }^{39}$ Furthermore, access to technological devices may not equate to comfort in using such devices. ${ }^{10}$ Health care providers must be careful not to ostracize patients who are unable or unwilling to develop their technological competence and ensure that the quality of care they receive is not compromised. Clinicians have a responsibility to educate and support patients who are willing to participate in virtual care. Investing in educating patients who are open to attempting virtual care yet lack digital literacy may help to bridge the digital divide.

First Nations patients are particularly affected by the digital divide. In a report published in 2021, it was found that "only $24 \%$ of households in Indigenous communities have access to quality, high-speed Internet," compared with $97 \%$ of urban households having access to high-speed Internet. ${ }^{45}$ This digital divide poses an additional barrier for First Nations patients, many of who are already situated in remote locations and have multiple comorbidities. The introduction of targeted grant programs to support marginalized communities seek health care through appropriate channels may provide a foundation to narrow the digital divide.

Beyond the digital divide for patients, clinicians also face challenges adapting to technological developments. Most health care providers receive little to no formal training during their education in delivery of care virtually. It is evident that virtual care will remain a significant part of health care beyond the COVID-19 pandemic; thus, future health care professionals should receive dedicated training to ensure virtual care is delivered effectively and safely. Care providers should receive training from their institutions and regulatory organizations with ongoing supplemental training as new technology and policies become available. The Virtual Care Task
Force was created in March 2019 by the Canadian Medical Association, the College of Family Physicians of Canada, and the Royal College of Physicians and Surgeons of Canada. Its mission is "to optimize the use of virtual care tools and platforms by physicians and patients in a way that meets patient needs and satisfies physician concerns. ${ }^{1,46}$

\section{Language barriers}

Canada is an incredibly linguistically diverse country. More than 200 languages were reported in the 2011 Census as a home language or mother tongue; $17.5 \%$ of the Canadian population, or 5.8 million persons, reported speaking at least 2 languages at home. ${ }^{47}$ Non-English language has been found to be independently associated with $>50 \%$ less use of virtual care, ${ }^{48}$ and patients identifying a non-English language as the preferred language was associated with 16\% fewer virtual care visits. ${ }^{13}$ Clearly, virtual care requires easily accessible interpretation services not only during the appointment but also throughout the entire encounter: from scheduling to followup. ${ }^{48}$ For example, to minimize language barriers, British Columbia now provides virtual interpreter services in 200 languages. ${ }^{49}$ Providing translated instructions that guide patients through the virtual care appointment process is crucial in ensuring that language barriers do not prevent patients from receiving appropriate care. Patients with functional illiteracy should receive verbal guidance from trained providers to assist them throughout their sessions.

\section{Billing and compensation}

The Canadian Institute for Health Information (CIHI) has provided a summary on physician billing codes for all Canadian provinces and territories in response to COVID-19, which can be accessed with the following link: https://www. cihi.ca/en/physician-billing-codes-in-response-to-covid-19. 
For example, virtual care fee codes in British Columbia have been established, with different codes depending on specialty. Within cardiology, there are different billing codes for various patient interactions including consultations, pacemaker testing, and implantable cardiac device monitoring. The full list of British Columbia fee codes can be found here: https://www.doctorsofbc.ca/sites/default/files/ telehealth_fees_-_by_section_0.pdf.

Within Ontario, temporary Ontario Health Insurance Plan (OHIP) billing codes ( $\mathrm{K}$ codes) have been released by the Ontario Ministry of Health and Ontario Medical Association to facilitate virtual care billing. This includes assessing and counselling via telephone or video. E-mails and text messages may also be used in patient care but are not discretely funded. ${ }^{50}$ The billing code K083 is meant for "specialist consultation or visit by telephone or video payable in increments of \$5.00," in which the total increments eligible for payment is equal to the fee listed in the Schedule of Benefits for Physicians Services for the appropriate service, rounded to the nearest $\$ 5$, divided by 5 . The patient encounter, including the start and stop times, must be documented on the patient's medical record. Full details can be found on the Ontario Ministry of Health's InfoBulletin: https://www.health.gov.on. ca/en/pro/programs/ohip/bulletins/4000/bul4745.pdf.

Billing codes for virtual care in Alberta have been established, some of which have limitations and some of which do not. The full list of virtual codes can be found here: https:// www.albertadoctors.org/leaders-partners/ehealth/virtual-care\# codes.

Although billing codes have provided the foundation for CVC to be available as a long-term option in Canada, further developments need to be made to ensure its sustainability. For example, in the United States, organizations such as the Health Resources and Services Administration (HRSA) have developed grant programs to support the delivery of virtual care, particularly in rural and underserved populations (https://www.hrsa.gov/rural-health/telehealth). The implementation of similar programs within Canada may greatly improve accessibility of CVC to marginalized populations.

At present, most Canadian billing codes are only for telephone or video visits and are not applicable for remote patient monitoring (RPM). In contrast, the United States has billing codes that cover both general RPM and condition-specific RPM such as blood pressure and pulse oximetry. ${ }^{51,52}$ The introduction of RPM billing codes in Canada may have the potential to encourage continuity of holistic care beyond the limits of virtual, phone, or video-based interviews.

\section{Interprovince licensure}

Although virtual care may provide the platform for interprovincial and international patient encounters, health care providers must consider whether licensing requirements are met before engaging in these interactions. Each jurisdiction has its own guidelines, and although physicians are typically not permitted to deliver care to patients outside of their jurisdictions, the COVID-19 pandemic has led to some Colleges increasing flexibility on scope of practice. For instance, the College of Physicians and Surgeons of Nova Scotia now permits physicians licensed in Canada to provide virtual care to patients in Nova Scotia "unless specifically restricted from doing so by their home licensing body."

CMPA gives details about medico-legal assistance to physicians providing virtual care to patients outside of their jurisdiction and outside of Canada at this webpage: https:// www.cmpa-acpm.ca/en/covid19/telehealth-and-virtual-care.

\section{Perception of Virtual Care}

\section{Perception among patients}

The onset of the COVID-19 pandemic has caused a significant decrease in hospital admissions for acute coronary syndromes in many countries, owing - at least in part - to the fear of contracting COVID-19 infections while in hospital. ${ }^{54}$ The push toward rapid adoption of CVC to minimize risks has been met with both praise and concern. The implementation of CVC has the potential to reduce the number of in-person visits, patient costs by minimizing costs associated with travelling, and time spent away from work, although further studies, systematic reviews, and meta-analyses are required. ${ }^{55}$ Patients remain concerned about privacy, as well as the costs associated with accessing technology and devices in patients who come from lower socioeconomic backgrounds or rural communities. ${ }^{13,39,55}$ Studies published in 2021 have reached conflicting conclusions; 1 study found patient satisfaction to be comparable between CVC and in-person appointments with similar no-show rates, ${ }^{56}$ whereas another study on heart failure CVC found that patients perceive their virtually delivered care to be of inferior quality compared with in-person appointments. ${ }^{57}$ A nationwide survey conducted in 2020 by the Canadian Medical Association (CMA) found that patient-satisfaction levels with virtual appointments were high, and only marginally below satisfaction levels of in-person visits. ${ }^{58}$ Despite developments in CVC, there will be patients who will not adopt virtual health strategies; further study is needed to identify ways to best provide care for these patients.

\section{Perception among health care providers}

A survey conducted by the American College of Cardiology found that nearly $90 \%$ of surveyed cardiologists were new virtual care users, although 68\% expressed awareness of virtual care reimbursement regulations within their state. ${ }^{59}$ A study showed that a significant concern from health care professionals is the inability to complete a thorough physical examination remotely and the dependence on patient knowledge, potentially allowing important findings to be missed. ${ }^{68}$ Remote assessments of jugular venous pressure (JVP) using social media apps and interpreted by advanced heart failure cardiologists were found to be comparable with bedside JVP estimation, with significant correlation to right atrial pressure measured by right-heart catheterization; however, evaluators expressed lower confidence on remote assessments compared with bedside ${ }^{61}$ Remote interpretation of cardiac auscultation is another area being investigated; a study conducted in rural China on the utility of asynchronous remote cardiac auscultation interpretation was shown to be $78.5 \%$ sensitive and $92.6 \%$ specific in identifying pathologic murmurs in children. ${ }^{62}$ Health care providers have expressed 
concerns about the decreased ability to form strong patientphysician relationships but cited a greater potential for increased frequency of interactions, which could be particularly useful for high-risk patients. ${ }^{60}$

\section{Resources Available to Help}

Following are a number of useful resources available in Canada to facilitate the adoption and delivery of virtual care. The Heart and Stroke Foundation has published 2 documents: 1 for health care providers, which outlines recommendations on implementing virtual care in everyday practice, and an article for patients with a virtual health care checklist to help patients prepare for virtual care sessions.

Virtual Healthcare Implementation Toolkit for health care providers: https://www.heartandstroke.ca/-/media/1-strokebest-practices/csbpr7-virtualcaretools-13may2020.ashx?rev = f2290bb992f14a3bb59e1b91bec6e310

Virtual healthcare checklist for patients: https://www. heartandstroke.ca/-/media/1-stroke-best-practices/resources/ patient-resources/csbp-infographic-virtual-healthcare-check list.ashx? rev = 4bdc5e8c2beb45af9af5e926dd6d0525

OMA has published numerous articles on navigating virtual care for health care providers. This article provides an overview on patient privacy, provincial fee codes, and patient consent: https://www.oma.org/newsroom/ontario-medicalreview/87-2/use-of-virtual-care-tools-during-covid-19/

The CMA published a Virtual Care Playbook for physicians in March 2020, detailing recommendations and strategies for providing safe and efficient virtual care: https://www. cma.ca/sites/default/files/pdf/Virtual-Care-Playbook_mar2020_ E.pdf

The CMA, Royal College of Physicians and Surgeons of Canada, and the College of Family Physicians of Canada have published a virtual care guide for patients. This guide provides important information such as which medical conditions are not appropriate for virtual care and how virtual care appointments are arranged: https://www.cma.ca/how-navigatevirtual-care-visit-patient-guide

\section{Future Developments}

\section{Integration of Internet of Things health care solutions}

Patients will be enabled to monitor certain signs in most settings and at most times via Internet of Things (IoTs), such as smart watches (Apple Watch, Fitbit, Garmin), smart and Internet-connected weight scales, blood pressure machines, and heart rhythm monitors (KardiaMobile; AliveCor, Mountain View, CA). This will allow health care professionals to monitor patients' health status remotely and provide timely feedback. With the integration of artificial intelligence, early warning alerts - such as abnormal blood pressure, weight gain, and abnormal rhythms - can be sent to both health care providers and patients to avert major clinical events. The integration of wearable and home-based devices could allow for greater personalization of health care interactions and continuity of care. ${ }^{63}$ Considerable study is still required to determine which data-in what quantities and at what frequency-should be sent to health care providers to improve outcomes. Furthermore, it is crucial to highlight the importance of clinically validated home-monitoring technologies. Although many devices claim to monitor health data accurately, many are not considered medical devices and thus are not subject to regulation by the Food and Drug Administration (FDA). ${ }^{64}$ Thus, the data collected from potentially inaccurate devices should certainly be interpreted with caution. Alternate FDA regulatory pathways have been developed during the COVID-19 pandemic; ${ }^{64}$ stringent regulations on appropriate clinical validation of medical devices should be implemented and enforced by Health Canada to ensure accurate monitoring of health data.

\section{Virtualization of health care}

Digital technology companies have been developing partnerships with major health systems. With the desire for fewer in-person interactions and appointments because of the pandemic, there has been increased uptake and acceptance of virtual care. Automation in virtual care can speed up routine tasks such as screening, triage, and prescription refills. ${ }^{65}$ Areas such as virtual diagnostics and digital home-care platforms have already been in development and may see broader implementation. The increasing availability and capability of smartphones has allowed for convenient portable virtual appointments and consultations. Platforms in Canada include Telus Health MyCare and Maple Virtual Care by Shopper's Drug Mart. Health care organizations in the United States have used virtual communication platforms for many years; these platforms have the potential to become prevalent within Canada in the near future. For example, Cleveland Clinic uses Doximity, ${ }^{66}$ whereas Mayo Clinic uses Medically Home.

The need for physically distanced patient interactions has expanded the role of disruptive technology in health care. Devices such as the HoloLens2 Mixed Reality headset (Microsoft, Redmond, WA) have been found to reduce health care workers' exposure time with potentially infectious patients as well as reduce the amount of personal protective equipment used. ${ }^{67}$ Medly, a heart failure self-management program partnered with University Health Network in Toronto, may be a promising means of providing patients with closer monitoring of their heart failure while collecting health data to assist clinicians in making clinical decisions regarding their care. ${ }^{68}$ In the United States, the TytoCare Medical Exam Kit (TytoCare, New York, NY) provides virtual urgent care with the opportunity for patients to conduct limited physical examinations from home (eg, heart and lung sounds, temperature, ear canal examination) interpreted by a remote health care provider using a specialized device. ${ }^{69}$ Virtual reality has the potential to supplement patient care, such as in health care provider training, patient education, and physical rehabilitation. $^{70}$

Various patients have different levels of acceptance of using virtual care as a method to communicate with their health care professionals. Based on authors' experiences, virtual health seems ideally suited in providing longitudinal care to stable patients. In-person visits may potentially be better suited to initial consults to allow for full physical examinations and to assess less stable patients for such symptoms as acute chest pain or acute shortness of breath. 


\section{Conclusions}

Canadian cardiovascular practitioners had virtual care thrust upon them by the distancing required by the COVID19 pandemic. Initially, the tools available at hand for virtual care were adapted to try and deliver services while minimizing their shortcomings compared with in-person care. A "new normal" state has started to emerge for individual practitioners, institutions, payers (governments), and administrators in which a significant portion of care will be virtual. These initial experiences of CVC need to be studied carefully in terms of cardiovascular outcomes as well as the processes of care delivery and their quality. There have been many successes with CVC delivery, but many initial concerns have been raised with respect to patient privacy, access to technology, language discrepancies, and provider remuneration. Cardiac diagnostic testing and therapeutic procedures remain mostly in the realm of in-person care. Nevertheless, the groundwork has been laid for virtual care to remain as a key modality for cardiovascular health care delivery in Canada. Ongoing study will be required to continue to refine and improve it and to understand its role alongside traditional in-person care.

\section{Funding Sources}

No funding has been received for this article.

\section{Disclosures}

The authors have no conflicts of interest to disclose.

\section{References}

1. Virtual Care Task Force. Virtual Care: Recommendations for scaling up virtual medical services. Available at: https://www.cma.ca/sites/default/ files/pdf/virtual-care/ReportoftheVirtualCareTaskForce.pdf. Accessed January 31, 2021.

2. Moulson N, Bewick D, Selway T, et al. Cardiac rehabilitation during the Covid-19 era: guidance on implementing virtual care. Can J Cardiol 2020;36:1317-21.

3. Tuckson RV, Edmunds M, Hodgkins ML. Telehealth. N Engl J Med 2017:1585-92.

4. Hu PT, Hilow H, Patel D, et al. Use of virtual visits for the care of the arrhythmia patient. Heart Rhythm 2020;17:1779-83.

5. Hardcastle L, Ogbogu U. Virtual care: enhancing access or harming care? Healthc Manag Forum 2020;33:288-92.

6. Statistics Canada. Life in the fast lane: How are Canadians managing? Published 2017. Available at: http://www.statcan.gc.ca/daily-quotidien/ 171114/dq171114a-eng.pdf\%0Ahttp://www.statcan.gc.ca/daily-quotidien/ 171114/dq171114a-eng.htm?HPA = 1. Accessed March 21, 2021.

7. Statistics Canada. Smartphone use and smartphone habits by gender and age group. Available at: https://doi.org/10.25318/2210011501-eng. Accessed April 25, 2021.

8. Statistics Canada. Internet use by province. Available at: https://doi.org/ 10.25318/2210008301-eng. Accessed April 25, 2021.

9. Clement J. Mobile usage in Canada: statistics \& facts. Statista, 2020. Available at: https://www.statista.com/topics/3529/mobile-usage-incanada/. Accessed April 25, 2021.
10. Lear SA. The delivery of cardiac rehabilitation using communications technologies: the "virtual" cardiac rehabilitation program. Can J Cardiol 2018;34:S278-83.

11. Anderson M, Perrin A. Tech adoption climbs among older adults. Washington, DC: Pew Research Center, 2017. Available at: https://www. pewresearch.org/internet/2017/05/17/technology-use-among-seniors/. Accessed May 24, 2021.

12. Glazier RH, Green ME, Wu FC, Frymire E, Kopp A, Kiran T. Shifts in office and virtual primary care during the early COVID-19 pandemic in Ontario, Canada. CMAJ 2021;193:E200-10.

13. Eberly LA, Kallan MJ, Julien HM, et al. Patient characteristics associated with telemedicine access for primary and specialty ambulatory care during the COVID-19 Pandemic. JAMA Netw Open 2020;3:e2031640.

14. Balady GJ, Ades PA, Bittner VA, et al. Referral, enrollment, and delivery of cardiac rehabilitation/secondary prevention programs at clinical centers and beyond. Circulation 2011;124:2951-60.

15. Banner D, Lear S, Kandola D, et al. The experiences of patients undertaking a "virtual" cardiac rehabilitation program. Stud Health Technol Inform 2015;209:9-14.

16. Buys R, Claes J, Walsh D, et al. Cardiac patients show high interest in technology enabled cardiovascular rehabilitation. BMC Med Inform Decis Mak 2016;16:1-9.

17. Lear SA, Singer J, Banner-Lukaris D, et al. Randomized trial of a virtual cardiac rehabilitation program delivered at a distance via the Internet. Circ Cardiovasc Qual Outcomes 2014;7:952-99.

18. Canadian Cardiovascular Society. The new "virtual reality": practical approaches to the delivery of cardiac rehabilitation care during the COVID-19 crisis. Available at: https://ccs.ca/app/uploads/2020/12/ Cardiac_Rehab_In_Covid_v2.4_Final_17_May_313.pdf. Accessed May 24, 2021.

19. Dalal HM, Doherty P, McDonagh ST, Paul K, Taylor RS. Virtual and in-person cardiac rehabilitation. BMJ 2021;373:n1270.

20. Khoury M, Phillips DB, Wood PW, et al. Cardiac rehabilitation in the paediatric Fontan population: development of a home-based high-intensity interval training programme. Cardiol Young 2020;30:1409-16.

21. Gawande A. Why doctors hate their computers. The New Yorker 2018;12:1-21. Available at: https://www.newyorker.com/magazine/ 2018/11/12/why-doctors-hate-their-computers. Accessed February 27, 2021.

22. Khullar D. Telemedicine is getting trendy, but doctors may not be keeping up. Washington Post, 2018. Available at: https://www. washingtonpost.com/national/health-science/telemedicine-is-getting-trendybut-doctors-may-not-be-keeping-up/2018/04/20/681e1644-2178-11e8badd-7c9f29a55815_story.html. Accessed February 27, 2021.

23. Shinbane JS, Saxon LA. Digital monitoring and care: virtual medicine. Trends Cardiovasc Med 2016;26:722-30.

24. Manimaran M, Das D, Martinez P, Schwartz R, Schilling R, Finlay M. The impact of virtual arrhythmia clinics following catheter ablation for atrial fibrillation. Eur Heart J Qual Care Clin Outcomes 2019;5:272-3.

25. Rush KL, Burton L, Van Der Merwe F, Hatt L, Galloway C. Atrial fibrillation care in rural communities: a mixed methods study of physician and patient perspectives. BMC Fam Pract 2019;20:1-11.

26. Lee M, Wang M, Liu J, Holbrook A. Do telehealth interventions improve oral anticoagulation management? A systematic review and meta-analysis. J Thromb Thrombolysis 2018;45:325-36. 
27. Zhang L, Babu SV, Jindal M, Williams JE, Gimbel RW. A patientcentered mobile phone app (iHeartU) with a virtual human assistant for self-management of heart failure: protocol for a usability assessment study. JMIR Res Protoc 2019;8:e13502.

28. Romano MF, Sardella MV, Alboni F, L'Abbate A, Mariotti R, Di Bello V. The informative contribution of the "virtual medical visit" in a new heart failure telemedicine integrated system. Telemed e-Health 2014;20:508-21.

29. Idris S, Degheim G, Ghalayini W, Larsen TR, Nejad D, David S. Home telemedicine in heart failure: a pilot study of integrated telemonitoring and virtual provider appointments. Rev Cardiovasc Med 2015;16: 156-62.

30. Deka P, Pozehl B, Williams MA, Norman JF, Khazanchi D, Pathak D. MOVE-HF: an internet-based pilot study to improve adherence to exercise in patients with heart failure. Eur J Cardiovasc Nurs 2019;18: $122-31$.

31. Uminski K, Komenda P, Whitlock R, et al. Effect of post-discharge virtual wards on improving outcomes in heart failure and non-heart failure populations: a systematic review and meta-analysis. PLoS One 2018;13:e0196114.

32. Stokes J, Kannel WB, Wolf PA, D’Agostino RB, Cupples LA. Blood pressure as a risk factor for cardiovascular disease. The Framingham Study: 30 years of follow-up. Hypertension 1989;13(5 suppl). I-13.

33. Padwal R, Campbell NRC, Schutte AE, et al. Optimizing observer performance of clinic blood pressure measurement. J Hypertens 2019;37: $1737-45$.

34. Postel-Vinay N, Bobrie G, Savard S, et al. Home blood pressure measurement and digital health. J Hypertens 2018;36:2125-31.

35. Hammersley V, Parker R, Paterson M, et al. Telemonitoring at scale for hypertension in primary care: an implementation study. PLOS Med 2020;17:e1003124.

36. Tucker KL, Sheppard JP, Stevens R, et al. Self-monitoring of blood pressure in hypertension: a systematic review and individual patient data meta-analysis. PLOS Med 2017;14:e1002389.

37. Monahan M, Jowett S, Nickless A, et al. Cost-effectiveness of telemonitoring and self-monitoring of blood pressure for antihypertensive titration in primary care (TASMINH4). Hypertension 2019;73:1231-9.

38. Padwal R, Berg A, Gelfer M, et al. The hypertension Canada blood pressure device recommendation listing: empowering use of clinically validated devices in Canada. J Clin Hypertens 2020;22:933-6.

39. Anthony DL, Campos-Castillo C, Lim PS. Who isn't using patient portals and why? Evidence and implications from a national sample of US adults. Health Aff (Millwood) 2018;37:1948-54.

40. Siegel A. Protecting patient data in a virtual world: how to help safeguard health data from cybercriminals. Ontario Medical Review. Available at: https://www.oma.org/newsroom/ontario-medical-review/87-5/protectingpatient-data-in-a-virtual-world/. Accessed March 14, 2021.

41. Canadian Medical Protective Association. Smartphone recordings by patients: be prepared, it's happening. Duties and responsibilities: expectations of physicians in practice. Available at: https://www.cmpa-acpm. $\mathrm{ca} /$ en/advice-publications/browse-articles/2017/smartphone-recordingsby-patients-be-prepared-it-s-happening. Accessed August 6, 2021.

42. Ramsetty A, Adams C. Impact of the digital divide in the age of COVID19. J Am Med Inf Assoc 2020;27:1147-8.

43. Smith A. US smartphone use in 2015. Washington, DC: Pew Research Center, 2015. Available at: https://www.pewinternet.org/2015/04/01/ussmartphone-use-in-2015/. Accessed March 14, 2021.
44. Anderson M, Kumar M. Digital divide persists even as lower-income Americans make gains in tech adoption. Washington, DC: Pew Research Center, 2019. Available at: https://www.pewresearch.org/facttank/2019/05/07/digital-divide-persists-even-as-lower-income-americansmake-gains-in-tech-adoption/. Accessed March 14, 2021.

45. RBC Thought Leadership. Building bandwidth: preparing indigenous youth for a digital future. Available at: https://royal-bank-of-canada-21 24.docs.contently.com/v/building-bandwidth-preparing-indigenous-youthfor-a-digital-future-pdf. Accessed July 29, 2021.

46. Royal College of Physicians and Surgeons of Canada. Virtual care. Health Systems and Policy. Available at: https://www.royalcollege.ca/rcsite/ health-policy/advocacy/virtual-care-task-force-e. Accessed January 31, 2021.

47. Statistics Canada. Linguistic characteristics of Canadians, 2011. Census of Population, 2012. Available at: https://www12.statcan.gc.ca/censusrecensement/2011/as-sa/98-314-x/98-314-x2011001-eng.cfm. Accessed May 21, 2021.

48. Eberly LA, Khatana SAM, Nathan AS, et al. Telemedicine outpatient cardiovascular care during the Covid-19 pandemic: bridging or opening the digital divide? Circulation 2020;142:510-2.

49. BC Provincial Health Services Authority. Provincial Language Service. Available at: http://www.phsa.ca/our-services/programs-services/provinciallanguage-service. Accessed May 24, 2021.

50. Ontario Medical Association. Use of virtual care tools during COVID-19. Ontario Medical Review. Available at: https://www.oma.org/newsroom/ ontario-medical-review/87-2/use-of-virtual-care-tools-during-covid-19/. Accessed May 21, 2021.

51. Javed M. Remote patient monitoring (RPM) CPT codes to know in 2021. SenSights.AI, 2021. Available at: https://sensights.ai/remotepatient-monitoring-rpm-cpt-codes-to-know-in-2021/. Accessed May 21, 2021.

52. Centers for Medicare and Medicaid Services. CY 2021 Payment policies under the physician fee schedule and other changes to Part B payment policies. Fed Regist 2021;86:5020-2.

53. Canadian Medical Protective Association. Providing virtual care during the COVID-19 pandemic. 2020. Available at: https://www.cmpa-acpm. ca/en/advice-publications/browse-articles/2020/providing-virtual-careduring-the-covid-19-pandemic. Accessed March 21, 2021.

54. Samargandy SA, Al Garni TA, Almoghairi A, et al. Effect of covid-19 pandemic on the cardiac outpatients' perception of seeking medical advice. J Saudi Heart Assoc 2020;32:377-82.

55. Cyr M. OMA, government negotiating permanent virtual-care measures. HealthyDebate, 2020. Available at: https://healthydebate.ca/2020/06/ topic/negotiating-permanent-virtual-care/. Accessed March 21, 2021.

56. Singh A, Mountjoy N, McElroy D, et al. Patient perspectives with telehealth visits in cardiology during Covid-19: online patient survey study. JMIR Cardiol 2021;5:e25074.

57. Raman KS, Vyselaar JR. Patient-reported experiences in outpatient telehealth heart failure management. Cardiol Res 2021;12:186-92.

58. Canadian Medical Association. What Canadians think about virtual health care. Available at: https://www.cma.ca/sites/default/files/pdf/ virtual-care/cma-virtual-care-public-poll-june-2020-e.pdf. Accessed August 8, 2021.

59. American College of Cardiology. ACC survey finds robust interest in video-visitations, telehealth amidst COVID-19 pandemic. ACC News Story, February 1, 2021. Available at: https://www.acc.org/latest-incardiology/articles/2021/01/29/20/08/acc-survey-finds-robust-interest-invideo-visitations. Accessed March 21, 2021. 
60. Heyer A, Granberg RE, Rising KL, Binder AF, Gentsch AT, Handley NR. Medical oncology professionals' perceptions of telehealth video visits. JAMA Netw Open 2021;4:e2033967.

61. Kelly SA, Schesing KB, Thibodeau JT, Ayers CR, Drazner MH. Feasibility of remote video assessment of jugular venous pressure and implications for telehealth. JAMA Cardiol 2020;5:1194.

62. Pyles L, Hemmati P, Pan J, et al. Initial field test of a cloud-based cardiac auscultation system to determine murmur etiology in rural China. Pediatr Cardiol 2017;38:656-62.

63. Fera B, Korba C, Shukla M. The future of virtual health: Deloitte Insights. April 30, 2020. Available at: https://www2.deloitte.com/us/en/ insights/industry/health-care/future-of-virtual-health.html. Accessed March 21, 2021.

64. Gerke S, Shachar C, Chai PR, Cohen IG. Regulatory, safety, and privacy concerns of home monitoring technologies during COVID-19. Nat Med 2020;26:1176-82.
65. Pifer R. 3 big predictions for digital health in 2021. Healthcare Dive, 2021. Available at: https:/www.healthcaredive.com/news/3-big-predictions-for-digital-health-in-2021/593691/. Accessed March 21, 2021.

66. Cleveland Clinic. Cleveland Clinic COVID-19 response: digital health playbook. Available at: https://my.clevelandclinic.org//scassets/files/org/ landing/preparing-for-coronavirus/covid-response-digital-health-playbook. ashx?la=en. Accessed May 23, 2021.

67. Martin G, Koizia L, Kooner A, et al. Use of the HoloLens2 mixed reality headset for protecting health care workers during the COVID-19 pandemic: prospective, observational evaluation. J Med Internet Res 2020;22:e21486.

68. eHealth Innovation. Medly: living well despite heart failure. Available at: https://medly.ca/. Accessed May 30, 2021.

69. TytoCare. TytoCare Medical Exam Kit. Available at: https://www. tytocare.com/. Accessed May 30, 2021.

70. Singh RP, Javaid M, Kataria R, Tyagi M, Haleem A, Suman R. Significant applications of virtual reality for COVID-19 pandemic. Diabetes Metab Syndr Clin Res Rev 2020;14:661-4. 